\title{
Relações teórico-práticas na formação matemática de professores dos anos iniciais do ensino fundamental: velhos e novos desafios
}

\author{
Antonia Alves Pereira da Silva ${ }^{1}$ \\ Universidade Estadual do Piauí - UESPI \\ Maria Isabel Ramalho Ortigão ${ }^{2}$ \\ Universidade do Estado do Rio de Janeiro - UERJ
}

\begin{abstract}
RESUMO
A literatura específica tem sido recorrente em afirmar a necessidade de repensar a formação docente dos anos iniciais do ensino fundamental de modo geral e, especificamente, daqueles que ensinam Matemática. A formação desses profissionais vem se constituindo, ao longo de décadas, um campo de disputas de concepções em que as ambiguidades, contradições e indefinições presentes na legislação vigente para a formação de professores no curso de Pedagogia refletem tentativas de aliar interesses distintos. A Resolução $\mathrm{CNE} / \mathrm{CP} \mathrm{n}^{\circ}$ 02/2019 (BNC-Formação) carrega uma perspectiva de formação que enfatiza o ensino por competências, pautado na técnica e no conteúdo, comprometendo a ideia de unidade teoria-prática, entendida como práxis social. O texto discute a práxis na formação matemática de professores dos anos iniciais, tendo como pano de fundo uma pesquisa conduzida na Universidade Estadual do Piauí que visou investigar a dimensão teórico-prática no processo formativo do curso de Pedagogia. A investigação fez uso de entrevistas com docentes e grupo focal com discentes. A análise revela que a formação docente conduzida na perspectiva de unidade teoriaprática contribui para a reflexão do ser professor e orienta futuros professores a apreender a pensar criticamente, uma perspectiva que tende a ser apagada pelas tentativas de imposição de visões tecnicistas de formação, trazidas nesse "novo" documento legal.
\end{abstract}

Palavras- chave: Pedagogia; Matemática; Práxis.

\footnotetext{
${ }^{1}$ Doutora em Educação pela Universidade do Estado do Rio de Janeiro (UERJ, 2020). Professora da Faculdade de Educação da Universidade Estadual do Piauí (UESPI), Teresina, Piauí, Brasil. Rua João Cabral, 2.231 - Pirajá. CEP 64002-150,

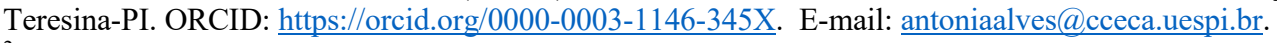

2 Doutora em Educação pela Pontifícia Universidade católica do Rio de Janeiro (PUC-Rio, 2005). Professora Titular da Faculdade de Educação da Universidade do Estado do Rio de Janeiro (UERJ), Rio de Janeiro, RJ, Brasil. Endereço para correspondência: Rua São Francisco Xavier, 524 - Sala 12037-F - Maracanã. CEP 20550-013, Rio de Janeiro-RJ. ORCID: http://orcid.org/0000-0001-7269-592X.E-mail: isabelramalhoortigao@gmail.com.
}

Revista de Educação Matemática (REMat), São Paulo (SP), v.19, Edição Especial, pp. 1-22, e022007, 2022, eISSN: 2526-9062 


\title{
Theoretical-Practical Relationships in Mathematical Training Provided to Early Elementary School Teachers: Old and New Challenges
}

\begin{abstract}
Studies available in the literature have repeatedly emphasized the need of rethinking the training provided to early elementary school teachers, most specifically to Mathematics teachers. For decades, the training provided to these professionals has been a field of disputes over concepts, wherein ambiguities, contradictions and uncertainties found in the current legislation on teachers' training in Pedagogy courses result from attempts to combine different interests. CNE/CP Resolution n. 02/2019 (BNC-Training) carries a training perspective focused on competence-based teaching, which is supported by technique and content, and compromises the theory-practice unity idea taken as social praxis. The aim of the current study is to address praxis in the mathematical training provided to early elementary school teachers, based on research conducted at State University of Piauí; such a research focused on the investigation about the theoretical-practical dimension of the training process adopted by Pedagogy courses. Interviews were conducted with teachers; a focus group was conducted with students. Based on data analysis, teachers' training - based on the theorypractice unity perspective - contributes to reflections about the meaning of being a teacher, as well as guides future teaching professionals in their critical thinking. However, such a perspective tends to be erased by attempts to impose technical perspectives about training that were brought forward in this 'new' legal document.
\end{abstract}

Keywords: Pedagogy; Mathematics; Praxis.

\section{Relaciones Teórico-Prácticas en la Formación Matemática de profesores de los Años Iniciales de la Educación Primaria: Viejos y Nuevos Retos}

\section{RESUMEN}

La literatura específica ha sido recurrente en afirmar la necesidad de repensar la enseñanza educativa de los años iniciales de la escuela primaria, en general y, específicamente, de quienes enseñan matemáticas. La formación de estos profesionales ha constituido, durante décadas, un campo de disputas de concepciones, en el que las ambigüedades, contradicciones e indefiniciones presentes en la legislación vigente para la formación de docentes en el curso de Pedagogía reflejan intentos de integrar intereses diferentes. La Resolución CNE/CP del 02/2019 (BNC-Formación) presenta una perspectiva formativa que enfatiza la enseñanza por competencias, basada en la técnica y el contenido, comprometiendo la idea de unidad teoría-práctica, entendida como praxis social. El texto discute la praxis en la formación matemática de los docentes de los años iniciales, en el contexto de una investigación realizada en la Universidad Estadista de Piauí, que tuvo como objetivo investigar la dimensión teórico-práctica en el proceso formativo del curso de Pedagogía. La investigación utilizó entrevistas con maestros y grupos focales con estudiantes. El análisis revela que la formación docente realizada en la perspectiva de la unidad teoría y práctica contribuye a la reflexión de ser docente y guía a los futuros docentes a aprender a pensar críticamente, perspectiva que tiende a ser anulada por los intentos de imponer visiones tecnicistas de formación, traídas en este "nuevo" documento jurídico.

Palabras clave: Pedagogía; Matemáticas; Praxis.

Revista de Educação Matemática (REMat), São Paulo (SP), v. 19, Edição Especial, pp. 1-22, e022007, 2022, eISSN: 2526-9062

DOI: $10.37001 /$ remat25269062v19id715

Sociedade Brasileira de Educação Matemática - Regional São Paulo (SBEM-SP) 


\title{
INTRODUÇÃO
}

Em 2019 foi publicada, no Brasil, a Resolução CNE/CP n 2/2019, que define as Diretrizes Curriculares Nacionais para a Formação Inicial de Professores para a Educação Básica e institui a Base Nacional Comum para a Formação Inicial de Professores da Educação Básica (BNC-Formação).

Essa publicação tem sido objeto de um alargado debate entre educadores, em especial por exprimir intenções políticas públicas de educação centradas na ideia de competências previstas na Base Nacional Comum Curricular (BNCC), assim como pelo fato de sua produção não ter envolvido discussões amplas advindas da comunidade de educadores. Ao contrário, sua elaboração ocorreu longe dos institutos democráticos da sociedade civil e sua publicação se deu no "apagar das luzes” do ano de 2019 (SILVA; ORTIGÃO, 2020), provocando impactos significativos na organização dos cursos de Licenciatura.

Farias (2019) salienta que a rapidez com que a proposta da BNC-Formação se desenhou no âmbito do governo e a ausência de informações para sociedade civil sobre o conteúdo dessa Proposta caracterizaram o que chamou de contrarreforma,

\begin{abstract}
processo encaminhado, desde o impeachment do governo de Dilma Rousseff, de maneira intempestiva e rompendo com processos coletivos de discussão e negociação legalmente constituídos, o que se materializou por interesses diversos, comprometendo aspectos e decisões democráticas, situação essa que é evidenciada, por exemplo, na própria elaboração e discussão da Base Nacional Comum Curricular - BNCC (FARIAS, 2019, p. 157).
\end{abstract}

Diferentemente do que está proposto na Resolução CNE/CP n ${ }^{\circ}$ 02/2019, entendemos a formação inicial de professores ofertada pelas Instituições de Ensino Superior (IES) como um processo de dimensão social significativo no qual esses profissionais possam colocar-se na condição de intelectuais, com responsabilidade e autonomia sobre o seu fazer pedagógico. Assim, defendemos que a formação de professores, em particular no curso de Pedagogia, deve pautar-se nos princípios de unidade teoria-prática, configurada como práxis, e numa perspectiva crítico-emancipatória.

Neste artigo discutimos a formação de professores dos anos iniciais do ensino fundamental tendo como base uma investigação que objetivou analisar o currículo do curso 
de Pedagogia da UESPI à luz dos seus elementos curriculares, identificando processos e práticas que, na percepção dos sujeitos, se desenvolvem numa perspectiva de unidade teórico-prática. Mais especificamente, analisamos depoimentos que evidenciam as percepções dos graduandos sobre a formação em Matemática ofertada no curso de Pedagogia da UESPI. Dada a centralidade da ideia de práxis (VAZQUEZ, 2011), esse conceito é discutido logo a seguir. Na sequência, refletimos sobre a formação de professores que ensinam Matemática nos anos iniciais e descrevemos a pesquisa que embasa a discussão. Por fim, a título de conclusão, discutimos o quanto as imposições advindas da BNCFormação têm se prestado mais ao pragmatismo e menos à práxis.

A discussão tem como pressuposto norteador a relevância da práxis como princípio epistemológico na formação inicial de professores, em particular na Pedagogia, compreendendo esse princípio como uma possibilidade para resistir às diversas tentativas de esvaziamento da formação docente, seja pela imposição de currículos centralizados e reducionistas, pelo cerceamento da pluralidade e diversidade cultural, seja pela negação da complexidade do processo educacional.

\section{A PRÁXIS NA FORMAÇÃO INICIAL DE PROFESSORES}

Em nossas reflexões acerca da formação docente, partimos da compreensão dessa atividade como uma práxis social que congrega de forma unitária uma teoria e uma prática. Portanto, a formação e a prática docentes são ancoradas na observação dos elementos conceptuais e práticos inerentes a ela. Nós nos referirmos à práxis compreendendo-a como Vazquez (2011), enquanto atividade teórico-prática que contempla, simultaneamente, um lado ideal e um lado propriamente prático; é, pois, unidade da teoria e da prática; é atividade objetiva que transforma a realidade natural e social. Implica, assim, uma ação consciente com finalidade cujo resultado foi previamente definido, ainda que no nível ideal. A atividade docente é práxis e o processo de formação de professores precisa estar referendado nesse princípio, numa epistemologia da práxis (SILVA, 2020; CURADO SILVA, 2017; VASQUEZ, 2021; NORONHA, 2010). 
A defesa da práxis como princípio epistemológico formativo no curso de Pedagogia está sustentada em duas ideias discursivas que se complementam: primeiro, a práxis como princípio da formação de professores concebido no âmbito da perspectiva crítica da Educação e promulgada pela Associação Nacional pela Formação dos Profissionais em Educação (ANFOPE); segundo, a compreensão da Pedagogia como área de conhecimento que tem na práxis educativa seu objeto de estudo.

No que tange ao primeiro aspecto, percebemos que, no debate sobre a formação de professores, a relação entre teoria e prática foi muitas vezes foco de discussões, dada a relevância dessas duas dimensões para a área. Na perspectiva crítica da educação, advogase que esses elementos sejam abordados de forma unitária, ou seja, enquanto práxis, visando a superar a histórica dicotomia presente no processo formativo. O entendimento desses aspectos de forma dicotomizada ou apenas justapostos (CANDAU; LELIS, 2011) na formação do pedagogo tem dificultado a compreensão da prática docente como práxis, incidindo, pois, na qualidade da atuação profissional.

Vários autores (CURADO SILVA, 2017, 2011; NORONHA, 2010; FRANCO, 2008; SAVIANI, 2008; FREIRE, 1987) têm discutido a prática educativa enquanto práxis. Franco (2008) destaca que, "na dimensão educativa, prática deve ser vista sempre no sentido de práxis educativa" (p. 80), que comporta uma dimensão ética, de intencionalidade que direciona a ação para transformar o objeto. Ela argumenta, fundamentada na concepção dialética, que teoria e prática não estão contrapostas e envolvem sempre dimensão e transformação do objeto e do sujeito.

Freire (1987) também compreende a prática docente como práxis, identificando-a como ação prática que não se confunde com o pragmatismo a-teórico, tampouco com um verbalismo que se distancia da vida prática, mas fundamentalmente como ação transformadora. "Práxis que, sendo ação e reflexão verdadeiramente transformadora da realidade, é fonte de conhecimento reflexivo e criação" (p. 92).

O pressuposto da educação e do trabalho docente enquanto práxis conduz à discussão da formação docente no sentido de uma epistemologia que tenha na práxis o seu norteamento, como propõe Noronha (2010). Para a autora, é necessário pensar a práxis como 
categoria epistemológica na formação dos professores, "o que nos levaria a uma diferenciação de fundo conceitual entre o que pode ser chamado de uma 'atividade de formação de professores' e uma 'práxis de formação de professores'; entre uma 'atividade educativa' e uma 'práxis educativa"” (NORONHA, 2010, p. 15).

Assim como Noronha, entendemos que pensar a formação docente é ponderar como o conhecimento é construído no âmbito desses cursos. Como a autora ressalta, pensar a questão das condições objetivas de formação de professores é colocá-la em termos de um problema de conhecimento. Para ela,

\begin{abstract}
ao tomar como ponto de partida que o conhecimento é construído no interior de uma pedagogia da práxis bem como a consideração do professor e do aluno como sujeitos históricos que, ao mesmo tempo que são modificados pelas circunstâncias, são capazes de nela atuar, modificando-as, torna-se possível que uma práxis transformadora possa ser desenvolvida no processo pedagógico de formação de professores e alunos (NORONHA, 2010, p. 17, grifos do original).
\end{abstract}

A adoção de uma epistemologia da práxis como princípio para formação de professores sustenta-se na ideia conceitual de que a prática educativa realizada nos diversos contextos educativos tem como propósito contribuir para a transformação dos sujeitos envolvidos.

Para Curado Silva $(2017 ; 2011)$, considerar a práxis como princípio formativo é defender uma formação docente comprometida com uma educação crítica emancipadora. A autora explicita que a formação nessa perspectiva se sustenta na compreensão do significativo papel da educação para construção da consciência crítica, necessária à análise da realidade. Nesse sentido, para a autora, a educação é compreendida como prática social de sujeitos concretos que atuam no sentido de transformação de sua realidade. Assim, ao professor é necessária a apropriação de elementos teórico-metodológicos para realizar a sua atividade profissional de forma crítica e politizada, a partir da análise e da síntese da realidade educacional, compreendendo as relações de poder existentes entre o espaço da escola e o contexto sociocultural mais amplo.

Discutimos até aqui, mesmo que brevemente, questões relativas à formação de professores, enfatizando a práxis como expressão da unidade entre teoria e prática. Defendemos que a formação de professores não pode prescindir de ter no horizonte a 
constituição de um professor com capacidades críticas, analíticas, reflexivas e criativas (CYRINO; GRANDO, 2021). Na continuidade, especificamos a discussão no âmbito do curso de Pedagogia, com foco na formação para o ensino de Matemática.

\section{A FORMAÇÃO DE PROFESSORES QUE ENSINAM MATEMÁTICA NOS ANOS INICIAIS}

Tipicamente, é nos cursos de Licenciatura em Pedagogia que se formam os professores e as professoras que atuarão na docência da educação infantil e dos anos iniciais do ensino fundamental para crianças, jovens ou adultos. Fazemos essa afirmação, contudo, sem a ideia de limitar a atuação dos licenciados em Pedagogia - reconhecendo, pois, que o curso de Pedagogia prepara não apenas para a área da docência, mas também para outras áreas de atuação, como a gestão de processos educacionais e a pesquisa em Educação, como previsto na LDBEN n ${ }^{\circ}$ 9.394/96 e na Resolução CNE/CP nº 1/06.

Os cursos de Pedagogia têm uma longa história, em que se pode perceber modificações significativas em sua concepção e estruturação (SILVA, 2020; COSTA, 2015; LIBÂNEO, 2001; 2006, dentre outros). Desde o final da década de 1970, em especial a partir do processo de redemocratização brasileira, após a ditadura militar, iniciam-se mudanças estruturais nos cursos de Licenciatura em Pedagogia objetivando uma formação para além da dimensão técnica da docência e numa perspectiva crítica em relação à sociedade, exigindo novas configurações curriculares e aprofundamento do debate acerca da identidade do pedagogo.

Em 2006, o Conselho Nacional de Educação publicou a Resolução CNE/CP n ${ }^{\circ}$, que instituiu as Diretrizes Curriculares Nacionais para o Curso de Licenciatura em Pedagogia. Essa Resolução, em seu Art. $4^{\circ}$, deliberou que o curso se destina à formação de professores para exercer funções de magistério na educação infantil e nos anos iniciais do ensino fundamental, nos cursos de ensino médio, na modalidade normal, de educação profissional na área de serviços e apoio escolar e em outras áreas nas quais sejam previstos conhecimentos pedagógicos. A Resolução define os espaços escolares e não escolares como campo de atuação do pedagogo e estabelece a docência como base de formação do curso de Pedagogia. O egresso

Revista de Educação Matemática (REMat), São Paulo (SP), v. 19, Edição Especial, pp. 1-22, e022007, 2022, 
do curso de Pedagogia deverá estar apto a “ensinar Língua Portuguesa, Matemática, Ciências, História, Geografia, Artes, Educação Física, de forma interdisciplinar e adequada às diferentes fases do desenvolvimento humano" (BRASIL, 2006, Art. 5).

A partir da publicação dessa Resolução, diversos estudos têm sido conduzidos com o intuito de compreender a formação no âmbito dos cursos de Pedagogia. Destacam-se nesse sentido a pesquisa de Gatti e Nunes (2008), que teceu um panorama de como tem se dado a formação do pedagogo no Brasil, tomando como referência a matriz curricular, e a ementa de 71 cursos de Pedagogia situados nas cinco regiões do país entre 2004 e 2006. Mesmo reconhecendo que esse estudo ocorreu em período anterior à publicação das DNCP, os resultados obtidos à época assinalaram a existência de um descompasso entre o que os cursos de Pedagogia ofereciam aos futuros professores e a realidade encontrada por eles nas escolas. Para as autoras, as IES se restringiam a preparar teoricamente o acadêmico, com pouco espaço para as áreas específicas envolvidas no trabalho docente nas escolas. Ou seja, eram frágeis as articulações entre teoria e prática na formação de professores nos cursos de Pedagogia, com exceção de disciplinas de metodologia e práticas de ensino.

Curi (2004) analisou a matriz curricular de 36 cursos de Licenciatura em Pedagogia com foco no conhecimento e nos saberes desenvolvidos para o ensino da Matemática e chegou a resultados similares. Para ela, em geral esses cursos contribuem pouco para que os futuros professores aprendam a conhecer a Matemática e seus processos de ensino e aprendizagem na escola básica. A autora chama a atenção para a carga horária destinada à formação em Matemática - em média de 36 a 72 horas -, o que corresponde de $4 \%$ a $5 \%$ da totalidade da carga horária analisada. Revela ainda que aproximadamente $90 \%$ dos cursos diagnosticados elegem as questões metodológicas como essenciais à formação do professor polivalente e que pouca importância é dada aos conteúdos matemáticos e suas didáticas nesses cursos. Para Curi (2004, p. 76-77),

é possível considerar que os futuros professores concluem cursos de formação sem conhecimentos de conteúdos matemáticos com os quais irão trabalhar, tanto no que concerne a conceitos quanto a procedimentos, como também da própria linguagem matemática que utilizarão em sua prática docente. Em outras palavras, parece haver uma concepção de que o professor polivalente não precisa "saber Matemática" e que basta saber como ensiná-la. 
A temática "Formação de professores que ensinam Matemática" foi foco do trabalho encomendado ao Grupo de Trabalho de Educação Matemática da Associação Nacional de Pós-Graduação e Pesquisa em Educação (ANPEd), no ano de 2008. À época, Muniz (2008) trouxe importantes considerações sobre a formação matemática no âmbito do curso de Pedagogia. Segundo o autor, a formação docente deve estar associada à atuação de grupos que desenvolvem pesquisas em Educação Matemática, permitindo ao futuro professor o desenvolvimento da investigação científica durante todo o processo de formação. Isso implicaria trazer para o contexto de formação a discussão dos saberes docentes e a análise de práticas pedagógicas. Assim, os acadêmicos dos cursos de Licenciatura em Pedagogia e Matemática podem,

não apenas por meio do ensino, mas também por ações de extensão contínuas, e de convivência com a pesquisa sob orientação de docentes da área de Educação Matemática, desenvolver outras concepções acerca da Matemática, seu valor formativo, cultural e social (MUNIZ, 2008, p. 25).

De modo geral, as discussões que envolvem a formação de professores alertam para a importância da articulação de teoria e prática, como evidenciam os três estudos exemplificados antes. Para nós, como já afirmado, essa articulação se expressa por meio da práxis pedagógica. A pesquisa que dá suporte às nossas reflexões visou a compreender essa práxis na formação em Pedagogia na UESPI. Na sequência descrevemos a pesquisa e discutimos os resultados.

\section{A PESQUISA}

O estudo que embasa este artigo foi conduzido pela primeira autora, no âmbito de seu doutoramento, tendo a coautora na orientação (SILVA, 2020). Seu objetivo principal foi analisar o currículo do curso de Pedagogia na Universidade Estadual do Piauí (UESPI), à luz dos seus elementos curriculares, identificando processos e práticas que, na percepção dos sujeitos, se desenvolvam numa perspectiva de unidade teórico-prática, entendida como práxis. 
A UESPI é uma instituição de ensino superior multicampi criada em 1986, com sede na capital do estado. Atualmente possui 12 campi e 12 núcleos. Nossa investigação focou exclusivamente o curso de Pedagogia do campus Torquato Neto, situado em Teresina.

A pesquisa considerou aspectos macrossociais e microcontextuais (LOPES, 2006; BRANDÃO, 2001) na produção do conhecimento e envolveu: (a) análise de documentos legais que subsidiam a formação em Pedagogia e do projeto pedagógico do curso (PPC); (b) entrevistas com oito professores responsáveis por disciplinas do segundo ao nono períodos; e (c) grupo focal envolvendo 48 estudantes matriculados nessas disciplinas.

Como abordagem metodológica, primeiro selecionamos as disciplinas a serem analisadas e, em seguida, convidamos os docentes responsáveis e os estudantes matriculados nelas a fazer parte do estudo. A estes foram fornecidas informações sobre os propósitos do estudo e garantidos sigilo e anonimato, como recomendado por Babbie (2005). Tanto as entrevistas dos docentes como o grupo focal com os estudantes pautaram-se em roteiros de questões abertas, construídos a partir do quadro de referência conceitual da pesquisa (SILVA, 2020; BABBIE, 2005; PEREIRA; ORTIGÃO, 2016).

No caso dos estudantes, as discussões por meio de grupo focal visaram a captar suas percepções sobre a própria formação, no que tange ao preparo para docência nos anos iniciais, notadamente em relação ao ensino de Matemática, Língua Portuguesa, Ciências, História e Geografia. As entrevistas com professores objetivaram conhecer como eles conduzem estratégias em salas de aula que possibilitam articulação teórico-prática. A seleção de disciplinas a serem investigadas abarcou os três eixos do currículo do curso Educação Infantil, Ensino Fundamental e Formação Pedagógica Geral -, como mostra o quadro a seguir. 
Quadro 1: Disciplinas selecionadas na pesquisa, de acordo com o eixo de formação e semestre em que são ministradas

\begin{tabular}{|llc|}
\hline Eixo de formação & Disciplinas & $\begin{array}{c}\text { Semestre em que a } \\
\text { disciplina é ministrada }\end{array}$ \\
\hline Educação Infantil & Educação Infantil & IV \\
& Currículo da Educação Infantil & V \\
& Estágio Supervisionado na Educação Infantil & VII \\
& Matemática: Conteúdo e metodologia & VI \\
Ensino Fundamental & Língua Portuguesa: conteúdo e metodologia & VI \\
& Estágio Supervisionado no Ensino Fundamental & VIII \\
& Filosofia da Educação II & II \\
& Didática & III \\
Formação & Teorias e Currículo & III \\
Pedagógica Geral & Fundamentos da Educação Especial & VIII \\
& Prática e Pesquisa Educacional IV & IX \\
& Estágio Supervisionado em Gestão Escolar & IX \\
\hline
\end{tabular}

Fonte: Silva, 2020.

Para o propósito deste texto, dado o foco de interesse e a limitação em número de páginas, discutimos aqui as possibilidades de constituição da unidade teoria-prática na disciplina Matemática: Conteúdo e Metodologia, ministrada no curso de Pedagogia na UESPI, a partir das falas dos estudantes e da professora da disciplina. Para análise, tomamos como referência de concepção docente a perspectiva crítico-emancipatória. Na sequência, discutimos os resultados obtidos.

\section{A FORMAÇÃO EM MATEMÁTICA NO CURSO DE PEDAGOGIA DA UESPI}

Os graduandos que participaram do grupo focal, grosso modo, afirmaram não se sentirem seguros para assumir a docência nos anos iniciais quando se trata do ensino dos conteúdos específicos, pois consideram haver pouca contribuição dessas disciplinas no sentido de prepará-los para a docência. Eles salientam as altas expectativas que tinham 
quando ingressaram no curso e que elas não foram contempladas, como exemplifica o depoimento a seguir.

A questão das disciplinas Matemática, Português, Ciências e História, essas aí a gente não sai do curso preparada para ministrar uma aula. Há necessidade de uma formação mais especifica, da gente estudar mesmo como ministrar uma aula porque o que a gente vê dentro do curso é pouco $(E 7 B 7)^{3}$.

Dada a alta incidência de falas que mencionavam a ausência de formação em conteúdo específico, indagamos se o curso deveria ter mais disciplinas com esse foco, ou seja, que abordassem mais o conteúdo. As respostas indicaram que não seriam mais disciplinas, mas o modo como trabalhar aqueles conteúdos com os alunos.

Seria, assim, a dinâmica como trabalhar Ciências, Matemática em sala de aula, porque o conteúdo mesmo a gente vai aprender é na prática, porque o professor tá constantemente estudando para poder ministrar (E7B7).

Evidencia-se aqui uma situação pedagógica na qual teoria e prática não foram conectadas, comprometendo a formação e a atuação futura do profissional docente no que tange à atuação nos anos iniciais do ensino fundamental, como apontam as pesquisas de Curi (2004) e as discussões de Curado Silva (2011; 2017).

Em diversas situações, foi-nos possível perceber concepções equivocadas que se perpetuam nos cursos de formação. Nas falas, os estudantes, grosso modo, evocaram a ideia de que a universidade deveria focar "a dinâmica de como trabalhar", pois "o conteúdo propriamente dito eles aprenderiam na prática e estudando". Subentende-se, dessa compreensão, que é possível aprender uma forma de ensinar determinado conteúdo sem a propriedade dele, em uma nítida separação de forma e conteúdo (CURADO SILVA, 2018; GATTI; NUNES, 2008).

Em seus depoimentos sobre Matemática, os alunos apontam inseguranças, mas apresentam uma fala diferenciada em relação às demais disciplinas; salientam o aprendizado de conteúdos que não havia ocorrido no ensino fundamental e a estratégia dinâmica de ensino adotada pela professora.

\footnotetext{
${ }^{3}$ Por opção metodológica, na pesquisa os estudantes foram identificados por códigos. Por exemplo, E7B7 indica Estudante, Número do estudante, Bloco da disciplina.
} 
Na questão da aula de Matemática que nós tivemos foi outra forma de aprender e ensinar Matemática que até nós, depois de adultas, estávamos aprendendo de novo. A gente não aprendeu desde pequeno, a gente veio ver isso em uma disciplina no curso superior (E3B7).

Ao mesmo tempo que apontam a aprendizagem de conteúdos que já deveriam ter aprendido desde o ensino fundamental, os estudantes revelam estranhamento quando se deparam com perspectivas teóricas que não são percebidas no contexto das escolas em que estagiaram ou fizeram observações, como evidenciam os depoimentos a seguir.

No caso dos anos iniciais, quando as meninas falaram com a professora de Matemática, ela colocou bastante para a gente a teoria de Davydov. Eu nunca tinha visto na minha vida, como é que eu vou adaptar isso, sendo que nem eu nunca vi? (E6B7).

Em Matemática eu vi uma diferença porque realmente foi uma coisa que eu nunca tinha visto, foi bom, eu vi que foi uma base, mas ao mesmo tempo eu não vi tanta diferença de quando eu não tinha e depois que eu tive e fui para escola (E5B7).

Essas falas revelam um aparente paradoxo ou falso conflito entre teoria e prática. Se os estudantes avaliam que a teoria foi boa e que lhes permitiu aprender conteúdos que não sabiam, foi diferente em relação a outras disciplinas dos conteúdos específicos; então, por que não conseguem utilizá-la na prática nas escolas?

Essa questão aponta para algumas reflexões e possíveis explicações. Uma delas seria o não domínio dos conteúdos matemáticos a serem trabalhados na escola, em especial durante a experiência docente como estagiário. Outra possibilidade é pensarmos no contexto das escolas em que a prática docente se desenvolve. Nesse caso, nos referimos ao fato de os estagiários nem sempre realizarem sua prática docente de forma autônoma, utilizando abordagens teórico-metodológicas estudadas na Universidade ou em cursos de formação, abordagens estas muitas vezes distintas daquilo que ocorre nas salas de aula. Esse aspecto veio à tona, durante a pesquisa, quando os estudantes relataram que o trabalho nas escolas com as disciplinas de Matemática e Língua Portuguesa é direcionado àquilo que será exigido nos exames de avaliação externa, inclusive com restrições à atuação de estagiários nessas disciplinas. Com isso, fica comprometido o processo de formação do pedagogo como professor dos anos iniciais, considerando a escola como espaço teórico-prático formativo relevante e de materialização da práxis.

Um aspecto que chamou a nossa atenção durante todo o percurso da pesquisa referese à formação dos professores que ministram aulas das disciplinas específicas no curso de 
Pedagogia; é importante estarmos atentos às questões dos formadores de professores (OLIVEIRA, 2007). Refletir sobre esse tema pode ser uma alternativa para superar essa falta de vínculo que os estudantes apontam entre o conteúdo das disciplinas específicas e a Pedagogia.

Pimenta (2002) avalia que a dificuldade em fazer a mediação pedagógica, por parte dos professores das chamadas disciplinas específicas, está relacionada a uma não apropriação do sentido de educação, de um projeto de formação de professores que leve à reflexão sobre o sentido de ser professor e à finalidade da educação, reflexão essa agenciada pela ciência pedagógica e que ainda enfrenta resistências nos cursos de licenciatura. Cumpre destacar que, no caso da disciplina que os estudantes apontaram como fazendo esse vínculo, a professora responsável possui formação em Pedagogia e desenvolve estudos e pesquisa na área do ensino de Matemática. Possivelmente essa docente trabalhe na perspectiva apontada por Muniz (2008), articulando formação, investigação científica e práticas sociais e culturais em Educação Matemática.

Especificamente, a professora que trabalha com a disciplina de Matemática destacou que procura alternar discussão conceitual com propostas de atividades do tipo feira de conhecimento, microaulas e projetos realizados nas escolas como parte da carga horária prática da disciplina. $\mathrm{Na}$ sua opinião, a feira de conhecimento tem sido uma excelente oportunidade de construção de conhecimento, pois oferece um desafio extra aos alunos, uma vez que possibilita que elaborem uma gama mais diversificada de atividades para, posteriormente, apresentar para um público.

Esse conjunto de estratégias é importante para produção da práxis educativa e para apropriação dos saberes matemáticos. Oliveira (2007, p. 187), em sua tese de doutorado, apontou a relação entre a "atuação dos formadores e a influência significativa que eles podem exercer no processo de construção de saberes docentes dos futuros professores e na implementação de novas práticas de ensino de Matemática”. Para a autora, é necessário orientar os futuros docentes a pensar, refletir criticamente e aprender a ensinar.

Esse sentido de formação também é defendido por Muniz (2008) argumentando que ela não deve ocorrer somente por meio de ensino, mas por ações de extensão e pesquisa que 
possibilitem aos estudantes desenvolver outras concepções acerca da Matemática, seu valor formativo, cultural e social.

Em seu depoimento, a professora aborda também algumas representações que os estudantes de Pedagogia têm em torno da disciplina. Segundo ela,

em geral os alunos vêm com a ideia de que vão aprender Matemática no curso; por outro lado, às vezes se contradizem, querem trabalhar "o como fazer, a forma". Então eles dizem: "olha, dessa disciplina eu espero aprender Matemática", mas quando a gente vai trabalhar conceitos matemáticos o aluno se questiona: "eu quero saber como é que eu posso fazer para os meus alunos aprenderem". Ai a gente vê essa questão da separação e é aí que a gente traz a questão da unidade inclusive dessas duas categorias de conteúdo e forma, porque não dá para eu trabalhar um determinado conteúdo sem pensar em como ensinar esse conteúdo (Professora Marina) ${ }^{4}$.

Esse trecho confirma o que foi percebido no diálogo com os estudantes: há uma expectativa pela aprendizagem de conceitos fundamentais da Matemática, ao mesmo tempo que os estudantes percebem que não basta o domínio do conteúdo para ensinar e ilustraram isso a partir da experiência que tiveram com professores de formação específica.

Acreditamos que a expectativa que os estudantes expressam pode estar relacionada à percepção da própria fragilidade quanto ao domínio dos conteúdos dos anos iniciais. Etcheverria e Campos (2015), em texto em que discutem o ensino da Matemática nos anos iniciais do ensino fundamental, ressaltam que o domínio do conteúdo de uma matéria a ser ensinada não se resume ao domínio dos conceitos fundamentais daquela matéria; envolve também os processos de sua produção, do conhecimento didático do conteúdo e de currículo.

Em seu depoimento, a professora Marina afirma que a proposta de trabalho com a Matemática conduzida por ela envolve uma tentativa de desmistificar a ideia de que os textos são somente teóricos; que a academia é somente teoria, e o seu oposto seria a prática nas escolas. Ela fala sobre sua visão de teoria e prática:

A compreensão que tenho hoje não foi aquela que eu adquiri durante a minha formação [...]; atualmente tento trazer para os meus alunos a compreensão de que elas se constituem uma unidade; então os textos que eu trago para a sala de aula são imbuídos de prática (Professora Marina).

\footnotetext{
${ }^{4}$ Os docentes foram identificados por codinomes. 
Os licenciandos, mesmo com "alguma" percepção de que os textos ajudam a entender a prática, ressaltam que algumas questões não são suficientemente abordadas e há realidades que eles só percebem quando chegam às escolas, como ilustrado na fala a seguir.

Eu vejo que não está sendo discutido como deveria. Muitas vezes a gente tá trabalhando aqui, estudando um tema, ai nas observações na escola nos deparamos com situações que realmente nunca imaginávamos, como, por exemplo, crianças que têm pais usuários de drogas, são traficantes, eles mesmos vendem drogas; situações assim do tipo que nós não esperávamos encontrar (...); poderia ser mais discutido (E2B6).

As falas revelam o caráter da imprevisibilidade inerente à educação e de uma realidade educacional que se mostra complexa, dinâmica e de difícil apropriação. A esse respeito, Curado Silva (2017) salienta que o trabalho com a epistemologia da práxis oferece elementos para conhecimento e análise da realidade e suas contradições. Alerta, contudo, que é necessário compreender que a realidade não se constitui em uma presença objetiva e monolítica. Ou seja, é impossível a apropriação da realidade como totalidade; e acreditamos ser imprescindível que as estratégias de ensino enfatizem a relação entre o particular e o universal, explicitando que na realidade educacional manifestam-se os elementos da realidade social ampla.

Com base nos dados apresentados, é possível afirmar que, no que tange à concepção de formação em Matemática, o currículo da UESPI tem norteado uma perspectiva crítica da educação. Ao fazer essa consideração, não a estamos colocando em termos de verdade materializada, tampouco compreendemos que a formação docente seja resultado apenas do que um currículo formalizado possa expressar; estamos ressaltando que existem indicativos apontados pelos sujeitos de que há uma formação em curso que possibilita, por exemplo, compreender a Educação e a Educação Matemática num sentido amplo e que seu papel na sociedade é contribuir para a sua transformação.

As considerações trazidas até aqui e evidenciadas pelas propostas de formação no âmbito do curso de Pedagogia na UESPI corroboram a importância e a atualidade de discussões sobre a formação docente, em especial por possibilitar contrapontos às novas diretrizes para a formação de professores que se colocam no horizonte, a partir da Resolução $\mathrm{CNE} / \mathrm{CP} n^{0}$ 2/2019. Como finalização, trazemos uma reflexão sobre essa Resolução e suas implicações no campo formativo. 


\section{REFLEXÕES FINAIS}

Como afirmado no início do texto, a publicação da Resolução CNE/CP nº 2/2019, em substituição à Resolução $\mathrm{CNE} / \mathrm{CP} \mathrm{n}^{0}$ 2/2015, sem efetiva e ampla discussão com a comunidade da Educação, surpreendeu a todos nós. Esse novo documento passa a definir as Diretrizes Curriculares Nacionais para a Formação Inicial de Professores para a Educação Básica instituindo uma "nova" concepção de formação, trazendo implicações aos cursos de Licenciatura. Nesta seção, a título de conclusão, discutimos esse documento sem a preocupação de uma análise em profundidade. Aqui, trazemos somente aquilo que toca à concepção de formação de professor e de pedagogo, possibilitando contribuir para construção da práxis na formação.

De início destacamos que a BNC-Formação tem sido objeto de muito debate e críticas conduzidos em universidades e entidades que discutem a formação de professores (ANFOPE, ANPEd, ABdC e ANPAE, dentre outras). De modo geral, há fortes questionamentos sobre o fato de a aprovação da nova Resolução ter ocorrido ao largo da discussão histórica em torno da formação de professores realizada pelas entidades representativas de classe e em pleno processo de implementação da Resolução CNE/CP n ${ }^{\circ}$ $2 / 2015$, interrompendo um processo de construção democrática e de atendimento às principais expectativas históricas da categoria (DOURADO, 2015).

A BNC-Formação é elaborada em um cenário de produção de políticas educacionais ideologicamente articuladas com a lógica de mercado e com as visões mais conservadoras em termos de educação (SILVA; ORTIGÃO, 2020). Desse modo, a concepção de professor contida no documento resgata a ideia da formação por competências presente nas Diretrizes para Formação Docente do ano de 2002. Com isso, evidencia-se uma concepção de docente com ênfase na dimensão técnica, em detrimento da noção de conhecimentos que permite olhar a educação no seu sentido mais amplo, com as relações que interferem na educação escolar.

Ao enfatizar a formação por competências, no seu aspecto técnico, a unidade teoriaprática fica comprometida, pois o conteúdo prático ganha centralidade no processo de formação. Um exemplo desse fato é a carga horária destinada à aquisição de conteúdos 
específicos da BNCC -1.600h/a, de um total de $3.200 \mathrm{~h} / \mathrm{a}$ da carga horária dos cursos (BRASIL, 2019). Em todo o texto da BNC-Formação é ressaltado o seu propósito de formar professores capazes de viabilizar na prática escolar o cumprimento da BNCC. A formação é significada apenas como processo de aquisição de habilidades e competências necessárias que, supostamente, ao serem adquiridas durante a formação, permitirão aos futuros docentes o cumprimento daquilo que é exigido dos alunos da educação básica, que por sua vez são avaliados também em termos de competências.

Em relação ao curso de Pedagogia, a BNC-Formação ignora a Resolução CNE/CP $n^{0} 1 / 2006$, que define as Diretrizes Curriculares para Formação nesse curso, reduzindo-o à docência com previsão de cursos separados para formação de professores da educação infantil e para os anos iniciais do ensino fundamental. Não contempla nessa formação as funções de gestão educacional, o que se contrapõe à ideia de uma formação ampla e integrada do pedagogo, que situa teoria e prática como dimensões unitárias do fazer pedagógico (SILVA; ORTIGÃO, 2020). Afasta-se, portanto, de uma compreensão de pedagogo cujo objeto de trabalho é educação enquanto práxis social, em sentido amplo; e educação em suas múltiplas manifestações sociais e nos diversos espaços, escolar e não escolar.

Pensar a formação do pedagogo sob o norteamento legal da BNC-Formação compromete a possibilidade de uma formação voltada para práxis docente. Outrossim, projeta um sentido de prática enquanto pragmatismo, de um saber fazer desarticulado de questões como: Por quê? Para quê? Para quem? A proposição de destinar somente 800h/a, de um total de $3.200 \mathrm{~h} / \mathrm{a}$, ao estudo dos conhecimentos científicos, educacionais e pedagógicos que fundamentam a educação e as práticas educacionais (BRASIL, 2019) revela a intencionalidade de redução da reflexão teórica nos cursos.

Assim, ainda que concordemos com as críticas aos cursos de Pedagogia, no sentido de fragilidades quanto ao ensino dos conteúdos matemáticos do ensino fundamental, de maior prática desses conteúdos, entendemos que a acentuação do pragmatismo pedagógico não permitirá a superação dessa problemática. Defendemos que a formação do pedagogo para quaisquer de suas funções exige fundamentação teórica sólida acerca do seu objeto de trabalho, mas também uma profunda reflexão sobre esses conteúdos e as práticas e os contextos de aplicação. Percebemos nos dados empíricos coletados na pesquisa e trazidos neste texto alguns 
vislumbres desse pensamento em que conteúdo e forma se articulam, aliados a tentativas de reflexão sobre os conteúdos e a proposição de desafios aos discentes. Receamos que esse vislumbre possa se esgarçar com a adoção da BNC-Formação, a menos que se busquem formas de resistências aos pragmatismos que o documento carrega.

Por fim, não podemos terminar este texto sem mencionar o momento difícil em que nos encontramos, de grande turbulência na sociedade brasileira e na mundial. No Brasil, um momento marcado por tentativas de destruição e retrocessos em diversas áreas profissionais e da vida social, cultural e econômica, mas também marcado pela pandemia da COVID-19 e pela necessidade de isolamento social, que nos faz pensar que o mundo virou de pontacabeça. Aqui em nosso país, essa "virada" vem atrelada a um projeto político iniciado com o impeachment de 2016 e culminado com a chegada ao poder (pelo voto nas eleições de 2018) de um governo conservador de extrema-direita, que beira o fascismo. Um projeto que acirra o negacionismo, ataca as escolas e as universidades públicas com tentativas de cerceamento de seus projetos político-pedagógicos e com redução de financiamentos públicos. Um projeto que tenta tornar a formação de professores uma ação técnica, desvinculada do sentido de práxis. Diante de tudo isso, resistir e (re)existir, mais do nunca, se faz imperativo!

\section{REFERÊNCIAS}

BABBIE, E. Método de Pesquisas de Survey. Trad. Guilherme Cezarino. $3^{\text {a }}$ ed. Belo Horizonte: Ed. UFMG, 2005.

BRANDÃO, Z. A dialética micro/macro na sociologia da educação. Cadernos de Pesquisa, São Paulo, n. 113, p. 153-165, jul. 2001. Disponível em https://www.scielo.br/pdf/cp/n113/a08n113.pdf. Acesso em: 01 ago. 2019.

BRASIL. Ministério de Educação e do Desporto. Conselho Nacional de Educação. Resolução CNE/CP no 1/2006. Diretrizes Curriculares Nacionais para o Curso de Pedagogia. Brasília, 2006.

. Ministério de Educação e do Desporto. Conselho Nacional de Educação. Resolução CNE/CP no 02/2015. Define as Diretrizes Curriculares Nacionais para a formação inicial em nível superior e para a formação continuada. Brasília, 2015. 
- Ministério de Educação e do Desporto. Conselho Nacional de Educação. Resolução CNE/CP n 02/2019. Define as Diretrizes Curriculares Nacionais para a formação inicial de professores para Educação Básica e institui a Base Nacional Comum para Formação de professores da Educação Básica (BNC-Formação). Brasília, 2019.

CANDAU, V. M. F.; LELIS, I. A. A relação teoria-prática na formação do educador. In:

CANDAU, V. M. F. (Org.). Rumo a uma nova didática. 21ª ed. Petrópolis: Vozes, 2011.

CYRINO, M. C. da C. T.; GRANDO, R. C. (Des)Construção curricular necessária: resistir, (re)existir, possibilidades insubordinadas criativamente. Texto apresentado na ANPEd 2021, GT-19, na modalidade Trabalho Encomendado.

COSTA, R. A. R. Identidade do pedagogo: formação e atuação. In: EDUCERE - XII CONGRESSO NACIONAL DE EDUCAÇÃO. Curitiba, PUC-PR, 26 a 29 de outubro de 2015. Disponível em: https://educere.bruc.com.br/arquivo/pdf2015/16596_10509.pdf. Acesso em: 05 maio 2021.

CURADO SILVA, K. A. P. C. A formação de professores na perspectiva críticoemancipadora. Linhas Críticas, Brasília, v. 17, n. 32, p. 13-31, jan./abr. 2011. Disponível em: http://repositorio.unb.br/bitstream/10482/9461/1/. Acesso em: 2 jan. 2019.

CURADO SILVA, K. A. P. C. Epistemologia da práxis na formação de professores. Revista de Ciências Humanas - Educação, v. 18, p. 15, 2017. Disponível em: http://revistas.fw.uri.br/index.php/revistadech/article. Acesso em: 03 ago. 2019.

CURI, E. Formação de professores polivalentes: uma análise do conhecimento para ensinar Matemática e de crenças e atitudes que interferem na constituição desses conhecimentos. 2004. 278 f. Tese (Doutorado em Educação Matemática) - Faculdade de Educação Matemática, Pontifícia Universidade Católica de São Paulo, São Paulo, 2004.

DOURADO, L. F. Diretrizes Curriculares Nacionais para a formação inicial e continuada dos profissionais do magistério da educação básica: concepções e desafios. Educação e Sociedade, Campinas, v. 36, n. 131, p. 299-324, jun. 2015. Disponível em: http://www.scielo.br/scielo.php?pid Acesso em: 03 nov. 2019.

ETCHEVERRIA, T. C.: CAMPOS, T. M. M. Formação de professores que ensinam Matemática: uma discussão sobre as estratégias de resolução utilizadas pelos alunos dos anos iniciais. In: PARENTE, C. da M. D.; VALLE, L. H. L. do; MATTOS, M. J. V. de (Orgs.). A formação de professores e seus desafios frente às mudanças sociais, políticas e tecnológicas. Porto Alegre: Penso, 2015.

FARIAS, I. M. S. de. O discurso curricular da proposta para BNC. Revista Retratos da Escola, Brasília, v. 13, n. 25, p. 155-168, jan./maio 2019. Disponível em: http://www.esforce.org.br. Acesso em: 6 nov. 2019. 
FRANCO, M. A. A pedagogia como ciência da educação. $2^{\text {a }}$ ed. São Paulo: Cortez, 2008.

FREIRE, Paulo. Pedagogia do Oprimido. 17 ed. Rio de Janeiro: Paz e Terra. 1987.

GATTI, B. A.; NUNES, M. M. R. Formação de professores para o ensino fundamental: instituições formadoras e seus currículos. São Paulo: Fundação Carlos Chagas (Relatório final: Pedagogia), 2008.

LIBÂNEO, J. C. Diretrizes curriculares da Pedagogia: imprecisões teóricas e concepção estreita da formação profissional de educadores. Educação e Sociedade, Campinas, v. 27, n. 96, out. 2006. Disponível em: https://doi.org/10.1590/S0101-73302006000300011. Acesso em: 05 maio 2021.

LIBÂNEO, J. C. Pedagogia e pedagogos, para quê? 4ª ed. São Paulo: Cortez, 2001.

LOPES, A. C. Relação macro/micro na pesquisa em currículo. Cadernos de Pesquisa, v. 36, n. 129, p. 619-635, set./dez. 2006. Disponível em: https://www.scielo.br/pdf/cp/v36n129/a0636129.pdf. Acesso em: 2 abr. 2021.

MUNIZ, C. A. Políticas públicas e formação inicial e continuada de professores que ensinam matemática. 2008. Disponível em:

https://www.anped.org.br/sites/default/files/trabalho_encomendado__ gt19_cristiano alberto_muniz.pdf. Acesso em: 05 maio 2021.

NORONHA, O. M. Epistemologia, formação de professores e práxis educativa transformadora. Quaestio, Sorocaba, v. 12, p. 5-24, jul. 2010. Disponível em: http://periodicos.uniso.br/ojs/index.php/quaestio/article/view/176. Acesso em: 12 maio 2021.

OLIVEIRA, A. T. C. C. Saberes e práticas de formadores de professores que vão ensinar Matemática nas séries iniciais. 2007. 228 f. Tese (Doutorado em Educação) Departamento de Educação, Pontifícia Universidade Católica do Rio de Janeiro, Rio de Janeiro, 2007. Disponível em: https://www.maxwell.vrac.pucrio.br/colecao.php?strSecao=resultado\&nrSeq=10516@1. Acesso em: 05 maio 2021.

PEREIRA, G.; ORTIGÃO, M. I. R. Pesquisa quantitativa em educação: algumas considerações. Periferia, v. 8, n. 1, p. 66-79, 2016. Disponível em: https://www.epublicacoes.uerj.br/index.php/periferia/article/view/27341/19946. Acesso em: 05 maio 2021.

PIMENTA, S. G. O estágio na formação de professores: unidade teoria e prática? $5^{\mathrm{a}}$ ed. São Paulo: Cortez, 2002.

SAVIANI, D. A pedagogia no Brasil: história e teoria. Campinas: Autores Associados, 2008. (Coleção Educação e Memória). 
SILVA, A. A. P. A dimensão teórico-prática como princípio epistemológico formativo: possibilidades constitutivas da práxis pedagógica na proposta curricular do curso de Pedagogia da Universidade Estadual do Piauí. 2020. 242 f. Tese (Doutorado em Educação) - Faculdade de Educação, Universidade do Estado do Rio de Janeiro, Rio de Janeiro, 2020.

SILVA, A. A. P.; ORTIGÃO, M. I. R. O curso de Pedagogia e os retrocessos na legislação educacional: quais as possibilidades de formação crítica? Série Estudos, Campo Grande, v. 25, n. 55, p. 95-116, set./dez. 2020. Disponível em: http://dx.doi.org/10.20435/serieestudos.v0i0.1487. Acesso em: 05 maio 2021.

VAZQUEZ, A. S. Filosofia da práxis. 2a ed. São Paulo: Expressão Popular, 2011. 